\title{
Effects of the Oral Administration of SATIOLIPID on Metabolic Parameters in Type 2 Diabetes Patients
}

\author{
Kristina Schmidt ${ }^{1 *}$, Dirk Vetter ${ }^{1}$, Katja Wagenblaß ${ }^{1}$, Dominik Gartzke ${ }^{1}$, Christoph Hasslacher ${ }^{2}$, Justo Lorenzo \\ Bermejo $^{3}$, Martina Kraft ${ }^{2}$, Nadine Matuszis ${ }^{2}$ and Erhard G Siegel ${ }^{4}$ \\ ${ }^{1}$ Perora GmbH, Germany \\ ${ }^{2}$ Clinical Study Center, St. Josefskrankenhaus Heidelberg, Germany
}

${ }^{3}$ Institute of Medical Biometry and Informatics, University of Heidelberg, Germany

${ }^{4}$ Department of Internal Medicine, Gastroenterology, Diabetology and Nutrition Medicine, St. Josefskrankenhaus Heidelberg GmbH, Germany

Submission: June 06, 2020; Published: July 01, 2020

*Corresponding author: Kristina Schmidt, Perora GmbH, Im Neuenheimer Feld 51869120 Heidelberg, Germany

\begin{abstract}
Satiolipid is a patented formulation composed of soluble, highly viscous plant fiber (hydroxypropylmethylcellulose) and lipids. We investigated the effects of Satiolipid administration to type 2 diabetes patients on diabetes-relevant metabolic parameters and weight.

After an initial run-in period of eight weeks, 27 non-insulin-dependent type 2 diabetes patients received one sachet of Satiolipid twice daily for 12 weeks. The following parameters were measured: fasting blood glucose, HbA1c, stimulated insulin secretion (C-peptide, insulin level) and glucose values during a meal challenge test, body weight, blood lipids, blood pressure and eating behavior (questionnaire). Parameter changes were assessed by paired $t$-tests and mean differences with $95 \%$ confidence intervals.

Among the study participants, $70.4 \%$ showed lower HbA1c levels and $74.1 \%$ lost weight after Satiolipid treatment. We also noticed a metabolic improvement after Satiolipid treatment reflected in (1) a lower area under the glucose curve during the meal challenge test and (2) decreased insulin resistance index (HOMA-IR). $63 \%$ of the study participants felt more satiated after Satiolipid intake. The promising results of the non-drug therapy with Satiolipid warrant investigation in a larger collective.

Keywords: Satiolipid; Type 2 diabetes mellitus; Non-drug therapy; HbA1c; Dietary fiber; HPMC

Abbreviations: HbA1c: Glycosylated Hemoglobin; HOMA-IR: Homeostasis Model Assessment of Insulin Resistance; HPMC: Hydroxypropylmethylcellulose; BMI: Body Mass Index; HDL: High Density Lipoprotein; LDL: Low Density Lipoprotein; CI: Confidence Interval; SD: Standard Deviation; AUC: Area Under the Curve; N: Number of Patients
\end{abstract}

\section{Introduction}

In the treatment of overweight patients suffering from diabetes mellitus type 2 , dietary factors continue to play a major role alongside drug therapy or surgical interventions. In addition to a general reduction in calorie intake, the main goals of nutritional therapy are to reduce postprandial glucose levels and compensatory insulin increases as well as to positively influence the feeling of satiety. From a dietary point of view, the fiber content of the food plays a particular role. Studies have shown that the addition of viscous dietary fibers such as guar gum, psyllium or beta-glucan to meals can reduce postprandial glucose levels and, to a certain extent, also insulin secretion [1-3].
Disadvantages of food supplementation with these naturally occurring dietary fibers are commonly intestinal discomfort such as flatulence, cramping, constipation or diarrhea [4]. When using hydroxypropylmethylcellulose (HPMC), a semi-synthetically produced cellulose, these side effects occur less frequently as this fiber cannot be fermented $[5,6]$. In studies with only one single administration of HPMC before a test meal similar effects on glucose and insulin levels could be measured as with the administration of natural dietary fibers [7-9]. However, the influence on carbohydrate metabolism when HPMC is administered over a longer period of time has not yet been investigated. In the present study, 
the influence of a newly formulated HPMC-containing dietary supplement (SATIOLIPID) on diabetes-relevant metabolic factors, blood lipid levels and weight behavior was therefore investigated in people with type 2 diabetes when administered over a 12 week period. This is the first longterm investigation of the influence of daily HPMC administration on metabolic parameters in diabetic patients.

\section{Methods}

The initial study population comprised 31 type 2 diabetes patients visiting the outpatient diabetes clinic of the St. Josefskrankenhaus Heidelberg $\mathrm{GmbH}$, who fulfilled the following inclusion criteria: Type 2 diabetes history of at least 2 years, age between $40-75$ years, orally treated, stable metabolic control, i.e. HbA1c $7.0-9.9 \%$ and no change in medication in the previous three months, Body Mass Index (BMI) $28-35 \mathrm{~kg} / \mathrm{m}^{2}$. The exclusion criteria were: Other types of diabetes, treatment with insulin, acute metabolic imbalance, acute infection, acute or chronic intestinal disorder, antibiotic medication during the previous three months, systemic therapy with cytostatic agents, immunosuppressive drugs, cortisone-containing agents or antirheumatic substances, serious diseases such as tumor diseases, liver cirrhosis, cardiac insufficiency ( $>$ NYHA II), renal insufficiency (eGFR $<30 \mathrm{~mL}$ / $\mathrm{min}$ ) and previous gastrointestinal surgery.

Prior to the administration of Satiolipid, participants were screened during an 8-week run-in period for stable body weight and diabetic control. Stable patients started the treatment period and received one sachet of Satiolipid twice daily during 12 weeks. Satiolipid was taken 20 - 30 min before two main meals. Each Satiolipid sachet contained 4g HPMC, mono-, di- and triglycerides of fatty acids, thickener and a beverage powder (citric acid, sodium hydrogen carbonate, magnesium carbonate, corn starch, sorbitol, sodium cyclamate, saccharin sodium, riboflavin).

Demographic data, current treatment and complications were retrieved at the screening visit. Laboratory parameters were measured using routine laboratory tests that included $\mathrm{HbA1c}$ and glucose concentration as well as body weight and blood pressure every four weeks. Blood lipid concentrations (Cholesterol, HDL, LDL, Triglycerides) as well as patterns of insulin secretion (serum Insulin- and C-peptide concentration) and glucose levels were examined prior to the start of Satiolipid administration and on the last day of the study during a meal challenge test. The test was performed using standardized food components (Ensure Plus Drink $200 \mathrm{ml}$, containing $12.2 \mathrm{~g}$ protein, $39.3 \mathrm{~g}$ carbohydrates and $9.4 \mathrm{~g}$ fat) and patients did not consume Satiolipid on the day before testing. Blood samples were drawn prior to and 30, 60, 90 and 120 minutes after the drink consumption. The areas under the insulin and glucose curves were calculated. Insulin resistance was calculated using the HOMA-IR formula. Patient questionnaires were used to assess changes in dietary habits and stool consistency as well as gastrointestinal symptoms.

Demographic and clinical characteristics of the study participants were descriptively analyzed. Categorical variables were summarized in contingency tables with frequencies and percentages. Continuous variables were summarized using the sample size, mean, standard deviation, minimum and maximum. Differences in diabetes-related metabolic parameters, body composition, lipid levels, blood pressure and safety parameters before and after administration of Satiolipid were quantified by the mean differences with corresponding 95\% confidence intervals (CIs) and probability values from paired t-tests (p). The trapezoidal rule was used to calculate the area under the curve (AUC) of the plasma levels of glucose, C- peptide and insulin. Statistical analyses were implemented using SAS v9.4 and the R software environment for statistical computing and graphics.

The local ethics committee approved the study and written informed consent was obtained from all subjects prior to study participation.

\section{Results}

\section{Patient characteristics}

31 type 2 diabetes patients participated in the run-in study period. Two participants discontinued the study for personal reasons and two additional patients due to distracting irregular bowel movements, resulting in 27 study participants with complete study data.

Table 1 shows the demographic and clinical characteristics of the participants at the beginning of the study. The investigated collective represents a typical patient population with an average 12.4-year history of type 2 diabetes mellitus, grade 1 obesity (BMI $32.1 \mathrm{~kg} / \mathrm{m}^{2}$ ) and moderate metabolic control (average fasting glucose level $172 \mathrm{mg} / \mathrm{dl}$, average HbA1c $7.9 \%)$. The majority of the patients presented hypertension (85.2\%) and roughly one third (34.5\%) showed at least one cardiovascular complication.

For treatment of diabetes, most patients $(92,6 \%)$ received metformin, around half $(48,1 \%)$ were treated with SGLT2 inhibitors and roughly $40 \%$ with an incretin-based therapy. Statins were given in around half of the patients (48.1\%) to treat dyslipidemia. Hypertensive patients received mostly ACE-inhibitors/AT1- blockers (77,8\%) and beta blockers, around half $(48.1 \%)$ of these received additionally diuretics. All medications were kept stable throughout the study. Compliance regarding intake of Satiolipid was good in most patients $(81.5 \%)$ i.e. correct intake in $>90 \%$ based on sachet count. 


\section{Current Research in Diabetes \& Obesity Journal}

Table 1: Demographic and clinical characteristics at baseline.

\begin{tabular}{|c|c|c|c|c|c|}
\hline Variable & Unit & Mean & SD & Minimum & Maximum \\
\hline Number of Subjects & & 27 & & & \\
\hline Women/Men & & 18-Sep & & & \\
\hline Age & Years & 67 & 6 & 53 & 81 \\
\hline Diabetes duration & Years & 12.4 & 5.4 & 5 & 24 \\
\hline Body weight & $\mathrm{kg}$ & 94.8 & 10.9 & 76.5 & 119 \\
\hline BMI & $\mathrm{kg} / \mathrm{m}^{2}$ & 32.1 & 2.2 & 28.1 & 36.3 \\
\hline Blood pressure systolic & $\mathrm{mmHg}$ & 138.2 & 13.5 & 115 & 161 \\
\hline Blood pressure diastolic & $\mathrm{mmHg}$ & 76.5 & 7.1 & 62 & 91 \\
\hline Fasting plasma glucose & $\mathrm{mg} / \mathrm{dl}$ & 172 & 30.7 & 135 & 266 \\
\hline HbA1c (Turb) & $\%$ & 7.9 & 0.8 & 7 & 10.5 \\
\hline HbA1c (IFCC) & $\mathrm{mmol} / \mathrm{mol}$ & 63 & 9 & 53 & 92 \\
\hline Leucocytes & $/ \mathrm{nl}$ & 6.9 & 1.8 & 3.6 & 11.4 \\
\hline Hemoglobin & $\mathrm{g} / \mathrm{dl}$ & 14.9 & 1.3 & 12.5 & 17.2 \\
\hline Thrombocytes & $/ \mathrm{nl}$ & 224.4 & 68 & 124 & 359 \\
\hline GOT & $\mathrm{U} / \mathrm{l}$ & 29.6 & 17.4 & 12 & 102 \\
\hline GPT & $\mathrm{U} / \mathrm{l}$ & 34.8 & 16.7 & 17 & 87 \\
\hline Gamma GT & $\mathrm{U} / \mathrm{l}$ & 64.9 & 136.7 & 9 & 729 \\
\hline Bilirubin total & $\mathrm{mg} / \mathrm{dl}$ & 0.5 & 0.2 & 0.3 & 1 \\
\hline Lipase & $\mathrm{U} / \mathrm{l}$ & 49.9 & 30.1 & 16 & 163 \\
\hline Creatinine & $\mathrm{mg} / \mathrm{dl}$ & 1 & 0.2 & 0.7 & 1.6 \\
\hline Sodium & $\mathrm{mmol} / \mathrm{l}$ & 140.6 & 2.2 & 136 & 145 \\
\hline Potassium & $\mathrm{mmol} / \mathrm{l}$ & 4.7 & 0.4 & 3.7 & 5.4 \\
\hline
\end{tabular}

\section{Effects of Satiolipid on diabetes-related parameters}

Almost three quarters of the study participants (70.4\%) showed lower HbA1c levels after Satiolipid administration. The average HbA1c difference was $-0.24 \%(p=0.004)$ for all patients and it amounted to $-0.42 \%$ for patients that showed a HbA1c reduction (Table 2). The fasting glucose level of study participants was also lower after Satiolipid administration $(-8.3 \mathrm{mg} / \mathrm{dl})$, but the difference did not reach a $5 \%$ statistical significance level $(\mathrm{p}=0.11)$.

Table 2: Changes in diabetes-specific parameters after Satiolipid administration. "Mean before" refers to parameter values before treatment, mean differences were calculated considering the values before and after Satiolipid treatment.

\begin{tabular}{|c|c|c|c|c|c|c|c|}
\hline Variable & Unit & N & Mean Before & Mean Difference & $\mathbf{9 5 \%}$ & CI & $\mathbf{p}$ \\
\hline HbA1c (Turb) & $\%$ & 27 & 7.8 & -0.24 & -0.4 & -0.1 & 0.004 \\
\hline HbA1c (IFCC) & $\mathrm{mmol} / \mathrm{mol}$ & 27 & 61.6 & -2.6 & -4.3 & -0.8 & 0.006 \\
\hline Fasting glucose & $\mathrm{mg} / \mathrm{dl}$ & 27 & 169.5 & -8.3 & -18.6 & 2 & 0.11 \\
\hline Glucose 0min & $\mathrm{mg} / \mathrm{dl}$ & 27 & 169.4 & -8.2 & -18 & 1.5 & 0.1 \\
\hline Glucose 30min & $\mathrm{mg} / \mathrm{dl}$ & 27 & 225.3 & -12.7 & -26.9 & 1.4 & 0.07 \\
\hline Glucose 60min & $\mathrm{mg} / \mathrm{dl}$ & 26 & 254.3 & -12.1 & -27.9 & 3.7 & 0.13 \\
\hline Glucose 90min & $\mathrm{mg} / \mathrm{dl}$ & 26 & 255.9 & -12 & -25.5 & 1.5 & 0.08 \\
\hline Glucose 120min & $\mathrm{mg} / \mathrm{dl}$ & 27 & 246.3 & -16.2 & -33.7 & 1.3 & 0.07 \\
\hline AUC Glucose & $\mathrm{mg} / \mathrm{dl} \mathrm{x}$ min & 26 & 28.3 & -1.544 & -2.929 & -158 & 0.03 \\
\hline C-Peptide 0min & $\mathrm{nmol} / \mathrm{l}$ & 27 & 1.3 & -0.1 & -0.3 & 0.1 & 0.17 \\
\hline C-Peptide 60min & $\mathrm{nmol} / \mathrm{l}$ & 26 & 2 & 0 & -0.2 & 0.3 & 0.91 \\
\hline
\end{tabular}




\section{Current Research in Diabetes \& Obesity Journal}

\begin{tabular}{|c|c|c|c|c|c|c|c|}
\hline C-Peptide 120min & $\mathrm{nmol} / \mathrm{l}$ & 27 & 2.3 & 0.2 & -0.1 & 0.4 & 0.13 \\
\hline AUC C-Peptide & $\mathrm{nmol} / \mathrm{I}^{*} \mathrm{~min}$ & 26 & 228.8 & 2.4 & -22.2 & 27.1 & 0.84 \\
\hline Insulin 0min & $\mathrm{mlU} / \mathrm{l}$ & 27 & 17.3 & -2.4 & -5.6 & 0.9 & 0.15 \\
\hline Insulin 60min & $\mathrm{mlU} / \mathrm{l}$ & 26 & 45.6 & 1.5 & -9.6 & 12.5 & 0.79 \\
\hline Insulin 120min & $\mathrm{mlU} / \mathrm{l}$ & 27 & 45.3 & 5 & -5.1 & 15.2 & 0.32 \\
\hline AUC Insulin & $\mathrm{mlU} / \mathrm{l}^{*} \mathrm{~min}$ & 26 & 4.616 & 179 & -700 & 1057 & 0.68 \\
\hline HOMA-IR & & 27 & 7.3 & -1.2 & -2.7 & 0.3 & 0.12 \\
\hline
\end{tabular}

The plasma glucose levels in the meal challenge tests decreased after Satiolipid administration for all measurement points (Table 2). Incremental glucose levels after $30 \mathrm{~min}$ and peak glucose levels after 90 min were in trend $5.4 \%$ and $4.7 \%$ lower than before treatment ( $p=0.07$ and $p=0.08$ ). The area under the curve (AUC) of plasma glucose levels was significantly lower after administration of Satiolipid than before treatment $(-5.5 \%, \mathrm{p}=0.03)$.

Levels of insulin secretion and C-peptide did not change during meal challenge tests after Satiolipid administration, neither at the individual measurement points $(0,60$, and 120 minutes), nor considering the overall AUC. HOMA-IR values decreased after Satiolipid administration in $70.4 \%$ of the study participants by trend, the average difference in the whole study population was $-1.2(\mathrm{p}=0.12)$.

\section{Effects of Satiolipid on body weight (BMI), blood lipids and blood pressure}

Body weight decreased in three quarters (74.1\%) of the study participants after Satiolipid treatment, with an average weight reduction of $1.66 \mathrm{~kg}$ in these subjects. The average weight loss in the complete study population was $0.8 \mathrm{~kg}(\mathrm{p}=$ $0.03)$ and the average BMI reduction was $0.3 \mathrm{~kg} / \mathrm{m}^{2}(\mathrm{p}=0.04$; Table 3).

The lipid levels (total cholesterol, HDL and LDL cholesterol and triglycerides) as well as systolic and diastolic blood pressure values did not change after Satiolipid administration Table 3)

Table 3: Changes in body weight, lipid levels and blood pressure after Satiolipid administration. "Mean before" refers to parameter values before treatment, mean differences were calculated considering the values before and after Satiolipid treatment.

\begin{tabular}{|c|c|c|c|c|c|c|c|}
\hline Variable & Unit & $\mathbf{N}$ & Mean Before & Mean Difference & $95 \%$ & CI & $\mathbf{p}$ \\
\hline Body weight & $\mathrm{kg}$ & 27 & 95.1 & -0.8 & -1.5 & -0.1 & 0.03 \\
\hline BMI & $\mathrm{kg} / \mathrm{m}^{2}$ & 27 & 32.2 & -0.3 & -0.5 & 0 & 0.04 \\
\hline Cholesterol (total) & $\mathrm{mg} / \mathrm{dl}$ & 27 & 171.8 & 1.6 & -8 & 11.3 & 0.73 \\
\hline HDL Cholesterol & $\mathrm{mg} / \mathrm{dl}$ & 27 & 44.9 & 2 & -0.5 & 4.4 & 0.11 \\
\hline LDL Cholesterol & $\mathrm{mg} / \mathrm{dl}$ & 27 & 104.9 & -1.2 & -9.9 & 7.5 & 0.78 \\
\hline Triglycerides & $\mathrm{mg} / \mathrm{dl}$ & 27 & 216.7 & -12.3 & -33.8 & 9.1 & 0.25 \\
\hline Blood pressure systolic & $\mathrm{mmHg}$ & 27 & 134.6 & 0.4 & -4.8 & 5.6 & 0.89 \\
\hline Blood pressure diastolic & $\mathrm{mmHg}$ & 27 & 77.8 & -2.6 & -5.7 & 0.4 & 0.09 \\
\hline
\end{tabular}

\section{Effects of Satiolipid on eating habits and bowel movements}

According to the questionnaire about changes in mealtime habits, around one half (48.1\%) of the participants reported to eat smaller portions or to omit between-meal snacks during Satiolipid administration. Approximately two thirds of the participants $(=63 \%)$ reported increased satiety after meals when taking Satiolipid.

Regarding changes in "regular bowel movements", roughly one fourth of the participants (25.9\%) reported an improvement during Satiolipid treatment, while more than half of the patients did not experience any change in this respect $(55,6 \%)$. The remaining study participants $(18.5 \%)$ felt stool consistency to be "poorer" during Satiolipid administration, as well as generally looser than before participation.

\section{Discussion}

The 12-week administration of the dietary supplement Satiolipid leads to a significant reduction of HbA1c (- $0.24 \%$; $\mathrm{p}=0.004)$ and body weight $(-0.8 \mathrm{~kg} ; \mathrm{p}=0.03)$ in people with type 2 diabetes. In the meal challenge test we detected a delay of the initial glucose increase after Satiolipid treatment and a reduction of the area under curve over $120 \mathrm{~min}$ of glucose levels $(-5.5 \%, p=0.03)$. Levels of insulin secretion were not significantly affected.

Satiolipid consists of a combination of hydroxypropylmethylcellulose (HPMC) lipids and some flavor correcting ingredients. HPMC is a semi-synthetically modified cellulose which, similar to naturally occurring soluble dietary fibers, transforms into a highly viscous gel in conjunction with liquids. When ingested with food, this leads to an increased 
stretching of the stomach wall and slows down gastric emptying. Mechanoreceptors thus convey an increased feeling of satiety [10-12]. In the small intestine, bulking and changes in the viscosity of the chyme results in reduced contact with digestive enzymes on the one hand, and on the other hand the diffusion of digested food to the absorbing intestinal wall is hindered. Thus, the absorption of food components is delayed or even reduced. With a single premeal administration of HPMC in a dose of 1 - $10 \mathrm{~g}$, a dose-dependent reduction of glucose levels and sometimes also of insulin secretion after a test meal could be observed in overweight people with or without diabetes [7-9,13].

The present study shows that these effects, which were proven in acute test systems, can also be demonstrated during the long-term administration of HPMC and thus have an influence on $\mathrm{HbA1c}$ and body weight. While fasting glucose levels before and after Satiolipid administration showed no significant difference, postprandial glucose concentrations were lower at the end of the treatment period: AUC of glucose levels measured over 2 hours after test meal decreased significantly by $5.5 \%(\mathrm{p}<0.03)$. As a consequence of the reduced glucose levels, $70.4 \%$ of the participants experienced a decrease in $\mathrm{HbA1c}$ levels resulting in a reduction of $0.42 \%$ in this subgroup at the end of the study. For the total population a decrease of $0.24 \%$ of $\mathrm{HbA} 1 \mathrm{c}$ level could be shown. A reduction of the $\mathrm{HbA} 1 \mathrm{c}$ value of at least $0.3 \%$ under a therapeutic measure is considered clinically relevant [14].

About three quarters of the participants experienced a reduction of body weight, resulting in a decrease of $1.66 \mathrm{~kg}$ on average in this subpopulation. In the whole group the weight reduction was $0.8 \mathrm{~kg}(\mathrm{p}<0.03)$. Two thirds of the participants reported an increase in the feeling of satiety and this can be seen as the cause of weight reduction. The higher satiety level led to a reduced calorie intake in almost half of the subjects by either eating only smaller portions of meals or by omitting snacks between meals. It is unclear whether the feeling of satiety is mediated by gastric dilatation, delayed gastric emptying or by sending out hormonal satiety signals from the small intestine by means of cholecystokinin, GLP-1 or peptide YY, since no corresponding measurements were made $[15,16]$. However, it is known that long-chain fatty acids, which are also present in Satiolipid, stimulate the formation of these hormones $[17,18]$.

Meta-analyses of studies investigating the influence of naturally occurring dietary fibers such as guar gum, psyllium or beta-glucan on glucose metabolism in people with type 2 diabetes showed similar results compared to our study. At a mean treatment period of 8-12 weeks, Post et al, [3] found an absolute reduction of $\mathrm{HbA} 1 \mathrm{c}$ of $0.26 \%$, Silva et al, [2] of $0.55 \%$ and Jovanovski et al, [1] of $0.58 \%$. Fasting glucose decreased between $9.9 \mathrm{mg} / \mathrm{dl}$ and $15 \mathrm{mg} / \mathrm{dl}$ in the aforesaid studies, a finding that we could not detect. In the present study, no influence of Satiolipid administration on fasting and postprandial insulin levels could be demonstrated. Corresponding findings were also described in the metaanalysis by Jovanovski et al. [1]. The behavior of body weight was not investigated in the meta-analyses mentioned above.

The administration of Satiolipid showed no effect on blood lipid concentrations in the serum samples of all subjects in the present study. The findings in several studies with naturally occurring dietary fiber show diverse results in this respect [19-21].

As priorly mentioned, supplementation of meals with dietary fibers in higher doses can increase the chance of intestinal complaints in patients [4]. In the present study, more than half of the participants did not notice any change in their bowel habits, and about a quarter even felt an improvement compared to their situation prior the study. The remaining patients reported a generally looser stool consistency when taking Satiolipid, which was considered unfavorable. This could be the result of an intolerance to the amount of fiber or other ingredients of Satiolipid the patient's digestive tract was confronted with. Further investigations will show whether a gradual introduction of satiolipid at the beginning of the study can reduce unfavorable bowel habits.

\section{Conclusion}

The 12-week administration of Satiolipid translated into an improved diabetes control (lower HbA1c and postprandial glucose levels) and a reduction of body weight. Neither patterns of insulin secretion, nor the insulin resistance did change significantly. Two thirds of the study participants experienced greater satiety during Satiolipid administration and consumed smaller portions or omitted between-meal snacks. These preliminary, promising results need confirmation in larger randomized controlled studies.

\section{Acknowledgement}

This study was supported by perora GmbH, Im Neuenheimer Feld 518, 69120 Heidelberg, Germany.

\section{References}

1. Jovanovski E, Khayyat R, Zurbau A, Komishon A, Mazhar N, et al. (2019) Should Viscous Fiber Supplements Be Considered in Diabetes Control? Results from a Systematic Review and Metaanalysis of Randomized Controlled Trials. Diabetes Care 42(5): 755-766.

2. Silva FM, Kramer CK, de Almeida JC, Steemburgo T, Gross JL, et al. (2013) Fiber intake and glycemic control in patients with type 2 diabetes mellitus: a systematic review with meta-analysis of randomized controlled trials. Nutr Rev (71): 790-801.

3. Post RE, Mainous AG, King DE, Simpson KN (2012) Dietary Fiber for the Treatment of Type 2 Diabetes Mellitus: A Meta-Analysis. J Am Board Fam Med (25): 16-23. 
4. Bianchi M, Capurso L (2002) Effects of guar gum, ispaghula and microcrystalline cellulose on abdominal symptoms, gastric emptying, orocaecal transit time and gas production in healthy volunteers. Dig Liver Dis (34): 129-133.

5. Dressman JB, Adair CH, Barnett JL, Berardi RR, Dunn-Kucharski VA, et al. (1993) High molecularweight hydroxypropylmethylcellulose. A cholesterol-lowering agent. Arch Intern Med (153): 1345-1353.

6. Maki KC, Davidson MH, Malik KC, Albrecht HH, O'Mullane J, et al. (1999) Cholesterol lowering with high- viscosity hydroxypropylmethylcellulose. Am J Cardiol 84(10): 1198-1203.

7. Reppas C, Adair CH, Barnett JL, Berardi RR, DuRoss D, et al. (1993) High viscosity hydroxypropylmethylcellulose reduces postprandial blood glucose concentrations in NIDDM patients. Diabetes Res Clin Pract 22(1): 61-69.

8. Maki KC, Carson ML, Miller MP, Turowski M, Wilder DM, et al. (2007) High-viscosity hydroxypropylmethylcellulose blunts postprandial glucose and insulin responses. Diabetes Care 30(5): 1039-4103.

9. Maki KC, Carson ML, Miller MP, Turowski M, Bell M, et al. (2008) Hydroxypropylmethylcellulose and Methylcellulose Consumption Reduce Postprandial Insulinemia in Overweight and Obese Men and Women. J Nutr 138(2): 292-296.

10. Bergmann JF, Chassany O, Petit A, Triki R, Caulin C, et al. (1992) Correlation between echographic gastric emptying and appetite: influence of psyllium. Gut 33 (8): 1042-1043.

11. Wanders AJ, van den Borne JJ, de Graf C, Hulshof T, Jonathan MC, et al. (2011) Effects of dietary fibre on subjective appetite, energy intake and body weight: a systematic review of randomized controlled trials. Obes Res 12(9): 724-739.

12. Slavia J, Green H (2007) Dietary fibre and satiety. Nutr Bull (3): 3242.
13. Jenkins DJ, Wolever TM, Leeds AR, Gassull MA, Haisman P, et al. (1978) Dietary fibres, fibre analogues, and glucose tolerance: importance of viscosity. BMJ 1(6124): 1392-1394.

14.Food and Drug Administration (2008) Guidance for Industry. Diabetes Mellitus: Developing Drugs and Therapeutic Biologics for Treatment and Prevention. Rockville, MD, U.S. Department of Health and Human Services.

15. Beglinger C, Degen L (2006) Gastrointestinal satiety signals in humans \pm physiologic roles for GLP-1 and PYY? Physiol Behav 89(4): 460-464.

16.Cummings DE, Overduin J (2007) Gastrointestinal regulation of food intake. J Clin Invest 117(1):13-23.

17. Sternini C, Anselmi L, Rozengurt E (2008) Enteroendocrine cells: a site of 1 tas- tea in gastrointestinal chemosensing. Curr Opin Endocrinol Diabetes Obes 15(1): 73-78.

18. Matzinger D, Gutzwiller JP, Drewe J, A Orban, R Engel, et al. (1999) Inhibition off food intake in response to intestinal lipid is mediated by cholecystokinin in humans. Am J Physiol 277(6 Pt 2): R17181724.

19. Liatis S, Tsapogas P, Chala E, Dimosthenopoulos C, Kyriakopoulos $\mathrm{K}$, et al. (2009) The consumption of bread enriched with beta-glucan reduces LDL-cholesterol and improves insulin resistance in patients with type 2 diabetes. Diabetes Metab 35(2): 115-120.

20. Cugnet-Anceau C, Nazare JA, Biorklund M, Le Coquil E, Sassolas A, et al. (2010) A controlled study of consumption of b-glucan enriched soups for 2 monthsby type 2 diabetic free-living subjects. Br J Nutr 103(3): 422-428.

21. Chandalia M, Garg A, Lutjohann D, von Bergmann K, Grundy SM, et al. (2000) Beneficial effects of high dietary fiber intake in patients with type 2 diabetes mellitus. N Engl J Med (342): 1392-1398.

Your next submission with Juniper Publishers
will reach you the below assets
- Quality Editorial service
- Swift Peer Review
- Reprints availability
- E-prints Service
- Manuscript Podcast for convenient understanding
- Global attainment for your research
- Manuscript accessibility in different formats
( Pdf, E-pub, Full Text, Audio)
- Unceasing customer service
Track the below URL for one-step submission
https://juniperpublishers.com/online-submission.php

